\title{
The EMT spectrum and therapeutic opportunities
}

Dominic Chih-Cheng Voon ${ }^{1.2}$, Ruby Yun-Ju Huang ${ }^{3,4}$, Rebecca A Jackson ${ }^{5}$ and Jean Paul Thiery, $5,6,7$

${ }^{1}$ Institute for Frontier Science Initiative, Kanazawa University, Kanazawa, Ishikawa, Japan

${ }^{2}$ Division of Genetics, Cancer Research Institute, Kanazawa University, Kanazawa, Ishikawa, Japan

${ }^{3}$ Department of Obstetrics \& Gynaecology, National University Hospital, Singapore 119228, Singapore

${ }^{4}$ Cancer Science Institute of Singapore, National University of Singapore, Singapore 117599, Singapore

5 Department of Biochemistry, Yong Loo Lin School of Medicine, National University of Singapore, Singapore 117596, Singapore

${ }^{6}$ Inserm Unit 1186 Comprehensive Cancer Center, Institut Gustave Roussy, Villejuif, France

${ }^{7}$ CNRS UMR 7057 Matter and Complex Systems, University Paris Denis Diderot, Paris, France

\begin{abstract}
Carcinomas are phenotypically arrayed along an EMT spectrum, a developmental program currently exploited to understand the acquisition of drug resistance through a re-routing of growth factor signalling. This review collates the current approaches employed in developing therapeutics against cancer-associated EMT, and provides an assessment of their respective strengths and drawbacks. We reflect on the close relationship between EMT and chemoresistance against current targeted therapeutics, with a special focus on the epigenetic mechanisms that links these processes. This prompts the hypothesis that carcinoma-associated EMT shares a common epigenetic pathway to cellular plasticity as somatic cell reprogramming during tissue repair and regeneration. Indeed, their striking resemblance suggests that EMT in carcinoma is a pathological adaptation of an intrinsic programme of cellular plasticity that is crucial to tissue homeostasis. We thus propose a revised approach that targets the epigenetic mechanisms underlying pathogenic EMT to arrest cellular plasticity regardless of upstream cancer-driving mutations.
\end{abstract}




\section{The EMT spectrum}

Recent evidence has advanced and broadened the definition of epithelialmesenchymal transition (EMT) in human pathologies. Whilst earlier studies relied on the use of key epithelial and mesenchymal markers to detect its aberrant activation during pathogenesis, it now becomes clear that this is a not a simple binary decision to acquire either an epithelial or a mesenchymal state. Rather, pathological EMT manifests dynamic transitional states punctuated by metastable intermediates (Nieto et al., 2016). This chapter collates the current knowledge of the molecular mechanisms underlying this phenomenon, and discusses current efforts in the deployment and development of therapeutic interventions.

EMT is orchestrated by a core set of transcription factors (EMT-TFs), each having the ability to drive EMT via largely analogous genetic programmes. These include SNAI1/2, TWIST, and ZEB, among others. As reviewed elsewhere, a myriad of growth factor and developmental signals activate these EMT-TFs (Thiery et al., 2009). However, the precise reasons for why this highly controlled programme is aberrantly triggered at times are varied and often obscured. This is compounded by the inherent difficulty in quantifying the extent of the so-called "partial EMT" in each disease state-just exactly how stable is metastable? Such complexities present a formidable challenge in rational drug design. Indeed, with such variations, what works in one context or in a particular patient could be futile or harmful in another. Nevertheless, with fresh knowledge and the benefit of hindsight, certain principles have emerged.

Like with other examples of heterogeneity encountered in biology, there is also heterogeneity following the execution of the EMT programme. One explanation is that EMT heterogeneity results from a diverse mix of populations undergoing EMT at different rates and downstream to various cues. For example, circulating tumor cells (CTCs) isolated from breast cancer patients display a spectrum of epithelialmesenchymal hybrid features (Khoo et al., 2015; Yadavalli et al., 2017; Yu et al., 2013a), the composition of which varies significantly among patients and is greatly dominated by the underlying biology of the primary tumor. Along the clinical course, the epithelial-mesenchymal hybrid features of CTCs continue to evolve, further illustrating that the metastable state itself exists as a dynamic range of equilibrium. With this appreciation of EMT as a spectrum of different states, broader perspectives of how to manipulate the metastable state within each context can thus be provided.

\section{EMT Drug Discovery Platforms}

At the heart of each drug discovery platform is a cohesive concept. In the development of EMT-targeting therapeutics, the following approaches have been adopted: 1) killing cells that have undergone EMT; and 2) reversing EMT in metastable cells. It is worth noting here that while these approaches share a common purpose, the rationale for each is distinct.

\subsection{Targeting EMT-induced Cancer Stem Cells}

In addition to greater chemoresistance, cells that have undergone EMT bear increased stem-like traits in vitro (Mani et al., 2008; Morel et al., 2008) and in vivo (Guo et al., 2012); this observation raised the hope that targeting EMT could eradicate the rare 
self-renewing and multipotent "cancer stem cells" (CSCs) that persist following conventional chemotherapy. EMT is also associated with increased cell migration and resistance to anoikis, properties that are associated with tumor invasion and metastasis. Thus, the specific killing of cells that have undergone EMT is an attractive therapeutic strategy against CSCs.

To date, the most extensive and prominent EMT-targeting screen was performed on the HMLE series of immortalized human mammary epithelial lines. These lines have been well characterized in studies of cellular transformation (Elenbaas et al., 2001). This model system led to the discovery of the EMT-induced, tumor-initiating CSC, typified by their CD $44^{\text {high} / C D} 24^{\text {low }}$ phenotype (Mani et al., 2008; Morel et al., 2008). The production of these cells was shown to be achieved either through the forced expression of EMT-TFs (SNAI1, TWIST1 and ZEB1) or through a combination of growth factors and RNAi (shEcad) (Mani et al., 2008; Scheel et al., 2011).

A high-throughput screen in a 384-well format was conducted using an HMLE derivative line that was induced to undergo EMT by expressing shEcad. This screen identified the selective cytotoxic effects of salinomycin, a potassium ionophore hitherto known as an antibiotic, on the CSC subpopulation $>100$-fold relative to paclitaxel (Gupta et al., 2009). Subsequent studies revealed that salinomycin promotes the degradation of the Wnt co-receptor LRP6 (lipoprotein receptor related protein 6) by inhibiting its phosphorylation, thereby attenuating Wnt signaling (Lu et al., 2011). The HMLE plateform was further deployed in expanded screens identifying other candidate compounds, most notably ML239, which appears to target NF-kB signaling (Carmody et al., 2012). More recently, a synthetic derivative of salinomycin was shown to kill breast cancer stem cells by sequestering iron in the lysosome, thereby triggering ferroptosis (Mai et al., 2017).

However, despite these advances, there are potential drawbacks to the cytotoxic killing of carcinoma cells undergoing an EMT. First, the endpoint of their transition is often not a permanent mesenchymal state but rather a metastable intermediate state, thus rendering them difficult to target. Indeed, the spectrum of intermediate states exhibited by CTCs (Khoo et al., 2015; Yadavalli et al., 2017; Yu et al., 2013a) likely means that they are not an effective target. Second, cytotoxicity exerts a selective pressure, that may hasten the evolution of CSCs into alternative metastable states not sensitive to the drug.

\subsection{Reversing EMT in metastable cancer cells}

In using an EMT reversal approach, mesenchymal-like carcinoma cells are reverted to their epithelial-like (original) phenotype, thereby restricting the (acquired) selfrenewal and invasive properties of these cancer cells. However, few suitable models exist for testing non-cytotoxic, EMT-reversing agents. One platform used the NBT-II rat bladder carcinoma line to screen for compounds that could reverse growth factorinduced cell scattering (Chua et al., 2012). Though modest in scale, this screen identified non-cytotoxic compounds that target ALK5/TGFßR1, MAPK, Src, and PI3K to reverse the scattering phenotype without impacting cellular proliferation. Two of these compounds, PD0325901 and Saracatinib, enhanced mesenchymal to epithelial transition (MET) when used in combination in NSCLC lines (Chua et al., 2015). Two other pre-clinical studies have reported the anti-EMT activity of Src 
kinase inhibitors in ovarian and breast carcinoma cell lines (Huang et al., 2013; Vultur et al., 2008).

A mesenchymal derivative of the HMLE cell model has also been used to identify compounds that promote MET (Pattabiraman et al., 2016; Tam et al., 2013). In a high-throughput screen with a firefly reporter linked to the Cdh1/E-cadherin, the authors found that forskolin and cholera toxin effectively induced MET by activating protein kinase A (PKA) through elevating intracellular cyclic AMP. This, in turn, activates PHD finger protein 2 (PHF2), which demethylates histone H3K9me2 and H3K9me3 to de-repress epithelial markers and permanently reverse EMT driven by epigenetic mechanisms. Importantly, the resultant MET strongly abrogates the tumorinitiating capacity and increases the drug sensitivity of EMT-prone carcinoma lines of various tissue origins. A similar platform also utilized an epithelial marker promoter induction (EpI) screen to identify histone deacetylase inhibitors (HDACi) as a potent class of EMT reversing agents (Tang et al., 2016; Yun-Ju Huang and Yo-Yan Huang, 2016).

An inherent shortcoming of the conventional cell-based platforms is their inadequacy to model the complex tissue microenvironment in which EMT occurs in vivo. To mimic this, a co-culturing system employing modern microfluidics has been developed incorporating tumor spheroids in a 3-dimensional hydrogel scaffold (Aref et al., 2013). This model also allows for assessing the contribution of endothelial cells in the system. One could expect that, with continual advances in methodology, new facets of the EMT process and, therefore, new strategies of intervention, will be uncovered.

Several candidate EMT reversing agents are already available clinically, such as Saracatinib. Initially developed for the treatment of cancer, saracatinib is a dualkinase inhibitor, targeting Src and Bcr-Abl tyrosine kinases. Although saracatinib is well tolerated in humans and showed promising results in animal studies, its efficacy in clinical trials has been disappointing either alone or in combinatorial treatments (Kim et al., 2009; Puls et al., 2011). In view of this, the functionally related focal adhesion kinase (FAK) could be tested for EMT reversal properties, as an inhibitor PF-00562271 has shown encouraging signs in early clinical trials (Infante et al., 2012).

A further application of these EMT reversing inhibitors would be in combination with other drugs to generate synthetic lethality. Along these lines, small chemical inhibitors of various signaling pathways are currently being used in clinical trials for their anti-EMT activities. Amongst these, inhibitors targeting the TGF- $\beta$ pathway-a classical activator of EMT - have shown the most promise. Of note, the TGF- $\beta$ inhibitor, LY2157299 (Galunisertib), is in Phase II studies against glioblastoma and hepatocellular carcinoma (Brandes et al., 2016; Giannelli et al., 2016; Rodon et al., 2015). Activation of the AXL receptor is reported to aberrantly phosphorylate SMAD3 to induce EMT in HCC progression in collaboration with TGF- $\beta$ (Reichl et al., 2015). As such, the concurrent targeting of AXL and TGF- $\beta$ may prove superior to monotherapy aimed at interfering with TGF- $\beta$ signaling, and this warrants further investigation, especially given the current availability of AXL inhibitors in the clinic (Antony et al., 2016; Byers et al., 2013; Feneyrolles et al., 2014; Giannelli et al., 2016; Nieto, 2013). 
Broadly speaking, inhibitors targeting the major cellular signaling pathways often have an impact on the EMT status of the carcinomas, as these pathways are intimately linked with EMT during development (Thiery et al., 2009; Voon and Thiery, 2017). It is worth noting, too, the potential hazards of reversing EMT in disseminated tumor cells, as MET is already employed by these metastasized cells as a strategy to promote colonization at distal sites (Beerling et al., 2016; Nieto, 2013; Ocana et al., 2012; Tsai et al., 2012). Therefore, precautions should be observed in the use of EMT-reversing agents in the clinic and only within a clear therapeutic window.

While these drugs may have anti-EMT activities, they were developed to target cancer-driving mutations within these pathways (Table 1). In other words, their clinical benefits are seldom benchmarked against their overall contribution to EMTassociated tumorigenicity and plasticity. Ironically, their inability to completely abrogate EMT may eventually become a driving force behind chemoresistance against these drugs.

\subsection{EMT, epigenetics and chemoresistance}

Numerous studies have reported the presence of residual resistant cells following chemotherapy, and these cells have been associated with an EMT phenotype in clinical settings as well as in animal models (Byers et al., 2013; Fischer et al., 2015; Kitai et al., 2016; Manchado et al., 2016; Shao et al., 2014; Zheng et al., 2015). EMTassociated chemoresistance may also be accompanied with a switch to compensatory pathways, so that carcinoma cells can regain cellular homeostasis (Kitai et al., 2016; Manchado et al., 2016). Whilst the precise basis for the correlation between EMT and cell survival remains obscure, it is likely that intermediate EMT states offer attractive "safe havens" in which cell signalling can be re-wired to become independent of the targeted pathway. Here, the capacity to shift to an alternate and viable phenotype relies on the cell's EMT-endowed plasticity, often termed epithelial mesenchymal plasticity (EMP) (Byers et al., 2013; Nieto, 2013).

It has been proposed that intermediate states represent quasi-discreet epigenetic states, which are characterized by altered histone modifications on key loci such as Ecadherin/Cdh1 and miR-200 (Nieto et al., 2016; Tam and Weinberg, 2013). Accordingly, the same epigenetic machineries that mark these intermediate states are often implicated in the acquisition of chemoresistance. An important class of such histone modifiers are the polycomb group (PcG) repressor complexes, PRC1 and -2 . During EMT, the PRC2 complex is recruited to the CDH1 promoter by the EMT-TF SNAI1, whereby it catalyzes the trimethylation of histone H3K27 to repress Ecadherin expression (Herranz et al., 2008). The same complex is also responsible for the trimethylation and silencing of miR-200, which gives rise to chemoresistance (Ceppi et al., 2010; Lim et al., 2013; Sato et al., 2017; Tryndyak et al., 2010). PRC1 components, such as BMI1, are considered stem cell factors that support normal stem cells and their transformed counterparts (Park et al., 2004; Valk-Lingbeek et al., 2004). The upregulation of BMI1 during carcinogenesis was reported to induce EMT and the invasive phenotype, and this was mediated via its cooperative actions with TWIST1 on Cdh1 and INK4A (Song et al., 2009; Yang et al., 2010). 
Acetylation is another histone modification associated with EMT and chemoresistance. During cancer metastasis, the histone deacetylases (HDAC) 1 and 2-as part of the Mi-2-nucleosome remodeling and deacetylase (NuRD) repressive complex - are recruited by Snail and TWIST to the Cdh1 and Foxa1 promoters, leading to their repression, respectively (Fu et al., 2011; Peinado et al., 2004; von Burstin et al., 2009; Xu et al., 2017). However, various components of the NuRD complex, and specifically, the HDACs, will confer drug resistance to cancer cells (Fu et al., 2011; Li et al., 2014; Sakamoto et al., 2016). Consequently, HDAC inhibitors like vorinostat, mocetinostat, and valproic acid are currently being evaluated as antiEMT agents (Bruzzese et al., 2011; Caponigro et al., 2016; Lan et al., 2016; Meidhof et al., 2015; Sakamoto et al., 2016; Schech et al., 2015; Schobert and Biersack, 2017).

A similar correlation between EMT and chemoresistance is also observed for lysinespecific demethylases, such as LSD1, an emerging class of epigenetic modulators (Bennani-Baiti, 2012; Lei et al., 2015; Nagasawa et al., 2015). LSD1 modulates gene expression by removing methyl groups on lysine 4 or lysine 9 of histone H3 to repress or activate target promoters, respectively (Shi et al., 2004). In the context of EMT, the induction of EMT in mammary epithelial cells involves the recruitment of LSD1 by SNAI1 to promoters of E-cadherin, claudin and cytokeratin family genes, which targets them for repression (Lin et al., 2010a; Lin et al., 2010b). In recent years, the association of LSD1 expression with malignancy, chemoresistance, and poor survival has raised interest into the therapeutic potential of its inhibitors ( $\mathrm{Lv}$ et al., 2012; Nagasawa et al., 2015; Yu et al., 2013b; Zhao et al., 2012).

In addition to histone modification, DNA methylation patterns are altered during persistent, mutation-driven EMT during carcinogenesis (McDonald et al., 2011; Tam and Weinberg, 2013). A key mediator of these aberrations appears to be the teneleven translocation 1 (TET1) methylcytosine dioxygenase, which initiates the demethylation of DNA and is associated with tumorigenesis in many cancers (Fu et al., 2014; Song et al., 2013; Sun et al., 2013; Tsai et al., 2014). However, there is opposing evidence as to the role of TET1 in EMT-induced chemoresistance: TET1 has been reported to promote cisplatin-resistance through its induction of EMT in ovarian cancer (Han et al., 2017), but act as a barrier against EMT in mammary epithelial cells by de-repressing the miR-200 promoter (Song et al., 2013).

Finally, it warrants highlighting that the epigenetic states of the EMT intermediates are cooperatively maintained at multiple levels of epigenetic regulation, with all the usual regulatory elements and limitations of a complex network. For example, just as miR-200 is a target of PRC2-mediated repression, the PRC2 component Suz12 is conversely targeted by miR-200 (Iliopoulos et al., 2010; Lim et al., 2013). Moreover, a functional cross-talk between TET1 and NuRD during EMT is also likely, given their cooperation in vitamin $\mathrm{C}$-induced MET during somatic cell reprogramming (Chen et al., 2013). 
From a clinical perspective, the resistance of cancer cells by virtue of their EMT state necessitates targeting the compensatory pathways employed by the cells for their eradication. However, it is just as likely that the very same mechanisms will later give rise to resistance to a new drug. Hence, rather than targeting the ever-shifting compensatory growth factor pathways, it would seem a better idea to shutdown cellular plasticity. A major obstacle in this approach is that we have an incomplete grasp of the molecular underpinnings of this plasticity. Nevertheless, some cues can be drawn from the field of tissue stem cells, where recent data reveal a genetic programme in differentiated cells that promotes cellular plasticity. Modern lineage tracing studies have demonstrated that some differentiated epithelial cells possess an innate ability to de-differentiate in vivo, and gain multipotency under specific circumstances (Rios et al., 2016; van de Moosdijk et al., 2017). This phenomenon is most clearly seen during injury and tissue regeneration, but also during inflammation and at certain stages during post-natal development, such as in the mammary gland during pregnancy. Indeed, in specific instances, the induction of stemness is reliant on the co-activation of the EMT programme (Guo et al., 2012; Ye et al., 2015). And, although the precise reason for this association is not known, it is clear that the capacity for somatic cell reprogramming - which was dramatically demonstrated in the generation of induced pluripotent stem cells (iPSc) from terminally differentiated fibroblasts - is integral to tissue homeostasis (Gregorieff et al., 2015; Smith et al., 2016; Takahashi and Yamanaka, 2006; Tetteh et al., 2016; van Es et al., 2012). In this light, it is possible that our current investigation of EMT-associated plasticity and induction would converge on common molecular mechanisms. In other words, disease-associated EMT may be a pathological manifestation of aberrantly activated normal somatic reprogramming of differentiated cells into functional stem cells (Ye et al., 2015).

Such a model of common epigenetic pathways governing EMP and induced pluripotency (iP) indeed has the capacity to accommodate common observations between the two phenomena. A prime example of this would be the role of p53 as a barrier, whereby the loss of its function lowers the threshold for entrance into EMP just as it would enhance the iP efficiency (Ansieau et al., 2008; Austin et al., 2013; Hong et al., 2009; Kawamura et al., 2009; Marion et al., 2009; Mu et al., 2017). A significant part of this is mediated through the p53-miR-200 regulatory network, which features prominently in the regulation of EMP and iP (Chang et al., 2011; Hu et al., 2014; Kim et al., 2011; Song et al., 2013). A further common feature is the repressive effects exerted by lineage-determining transcription factors, such as BRIGHT/ARID3A, RUNX3, GRHL2 and PAX5 (Chung et al., 2016; Hanna et al., 2008; Hikichi et al., 2013; Popowski et al., 2014; Voon et al., 2012). Of relevance, both processes are governed by cell extrinsic factors, such as growth factors (Lluis et al., 2008; Thiery et al., 2009; van Es et al., 2012; Vidal et al., 2014), and intrinsic epigenetics elements, such as the TET/miR-200 axis (Hu et al., 2014; Song et al., 2013) and the NuRD repressor complex (Chen et al., 2013; dos Santos et al., 2014; Ebrahimi, 2015; Fu et al., 2011).

Despite these parallels, there are obvious differences between the induction of EMP in carcinoma and somatic reprogramming, specifically during the generation of iPSc from fibroblasts. Most notably, the induction of pluripotency in the case of the latter 
is preceded by MET. It reverts fibroblasts into an epithelial phenotype similar to that of embryonic stem cells (Li et al., 2010). Consistent with this, pro-EMT signals like TGF- $\beta$ (Ichida et al., 2009; Qin et al., 2014; Vidal et al., 2014), Wnt/ $\beta$-catenin (Ho et al., 2013; Lluis et al., 2008), and Hippo (Qin et al., 2012) pathways act as barriers against iP in a context-specific manner. At the same time, inhibitors of these pathways, such as the aforementioned anti-EMT TGF- $\beta$ inhibitors, strongly enhance the efficiency of somatic reprogramming (Ichida et al., 2009; Maherali and Hochedlinger, 2009). Overall, it seems EMP and iP each requires a phenotypic shift along the EMT spectrum (albeit, in opposite directions) towards an intermediate metastable state en route to dedifferentiation/reprogramming. If so, then it is imperative that the innate molecular barriers - such as oxidative and methylation states of the chromatin and their regulators, which safeguard against phenotypic slippage-are thoroughly elucidated. Ultimately, the promise of a plasticity-centric paradigm is its amenability to the precise targeting of EMT-associated plasticity in carcinomas irrespective of the upstream driver mutations, and invulnerable to the re-routing of the signalling circuit observed in current strategies. Accordingly, the development of these next-generation therapeutics will require discovery platforms that assay the functional output of the involved epigenetic machineries rather than, for example, the activation of a particular marker gene.

\section{Concluding remarks}

EMT has emerged in recent years to be a major driver of chemoresistance to anticancer therapies in the clinic. This is closely linked to phenotypic plasticity in the form of metastable intermediates over the EMT spectrum. The biological reason for this phenomenon is currently unclear, but it is possible that aberrant EMT in carcinoma cells unlocks an innate dedifferentiation programme integral to tissue repair, development, and homeostasis. Importantly, such an engine of plasticity would also fuel tumor heterogeneity, progression, and immune escape. Despite the clear need, targeting EMT in cancer therapy has proven challenging due to conceptual difficulties in the design of viable screens. Conventional screening approaches that focus on interfering with specific molecular interactions are unsuitable or have yielded inconsistent results. In this review, we surveyed the current efforts to develop and deploy anti-EMT therapeutics and discussed their relative effectiveness. By way of this evaluation, a novel concept is put forth to selectively inhibit low-order epigenetic mechanisms that promote plasticity. In doing so, the phenotypic flexibility that enables cancer cells to be "moving targets" will be greatly restricted, thereby enhancing the efficacies of current therapeutics.

\section{REFERENCES}

Ansieau, S., Bastid, J., Doreau, A., Morel, A.P., Bouchet, B.P., Thomas, C., Fauvet, F., Puisieux, I., Doglioni, C., Piccinin, S., et al. (2008). Induction of EMT by twist proteins as a collateral effect of tumor-promoting inactivation of premature senescence. Cancer Cell 14, 79-89.

Antony, J., Tan, T.Z., Kelly, Z., Low, J., Choolani, M., Recchi, C., Gabra, H., Thiery, J.P., and Huang, R.Y. (2016). The GAS6-AXL signaling network is a mesenchymal (Mes) molecular subtype-specific therapeutic target for ovarian cancer. Sci Signal 9, ra97. 
Aref, A.R., Huang, R.Y., Yu, W., Chua, K.N., Sun, W., Tu, T.Y., Bai, J., Sim, W.J., Zervantonakis, I.K., Thiery, J.P., et al. (2013). Screening therapeutic EMT blocking agents in a three-dimensional microenvironment. Integr Biol (Camb) 5, 381-389.

Austin, P., Freeman, S.A., Gray, C.A., Gold, M.R., Vogl, A.W., Andersen, R.J., Roberge, M., and Roskelley, C.D. (2013). The invasion inhibitor sarasinoside A1 reverses mesenchymal tumor transformation in an E-cadherin-independent manner. Mol Cancer Res 11, 530-540.

Beerling, E., Seinstra, D., de Wit, E., Kester, L., van der Velden, D., Maynard, C., Schafer, R., van Diest, P., Voest, E., van Oudenaarden, A., et al. (2016). Plasticity between Epithelial and Mesenchymal States Unlinks EMT from MetastasisEnhancing Stem Cell Capacity. Cell Rep 14, 2281-2288.

Bennani-Baiti, I.M. (2012). Integration of ERalpha-PELP1-HER2 signaling by LSD1 (KDM1A/AOF2) offers combinatorial therapeutic opportunities to circumventing hormone resistance in breast cancer. Breast Cancer Res 14, 112.

Brandes, A.A., Carpentier, A.F., Kesari, S., Sepulveda-Sanchez, J.M., Wheeler, H.R., Chinot, O., Cher, L., Steinbach, J.P., Capper, D., Specenier, P., et al. (2016). A Phase II randomized study of galunisertib monotherapy or galunisertib plus lomustine compared with lomustine monotherapy in patients with recurrent glioblastoma. Neuro Oncol 18, 1146-1156.

Bruzzese, F., Leone, A., Rocco, M., Carbone, C., Piro, G., Caraglia, M., Di Gennaro, E., and Budillon, A. (2011). HDAC inhibitor vorinostat enhances the antitumor effect of gefitinib in squamous cell carcinoma of head and neck by modulating ErbB receptor expression and reverting EMT. J Cell Physiol 226, 2378-2390.

Buck, E., Eyzaguirre, A., Rosenfeld-Franklin, M., Thomson, S., Mulvihill, M., Barr, S., Brown, E., O'Connor, M., Yao, Y., Pachter, J., et al. (2008). Feedback mechanisms promote cooperativity for small molecule inhibitors of epidermal and insulin-like growth factor receptors. Cancer Res 68, 8322-8332.

Byers, L.A., Diao, L., Wang, J., Saintigny, P., Girard, L., Peyton, M., Shen, L., Fan, Y., Giri, U., Tumula, P.K., et al. (2013). An epithelial-mesenchymal transition gene signature predicts resistance to EGFR and PI3K inhibitors and identifies Axl as a therapeutic target for overcoming EGFR inhibitor resistance. Clin Cancer Res 19, 279-290.

Caponigro, F., Di Gennaro, E., Ionna, F., Longo, F., Aversa, C., Pavone, E., Maglione, M.G., Di Marzo, M., Muto, P., Cavalcanti, E., et al. (2016). Phase II clinical study of valproic acid plus cisplatin and cetuximab in recurrent and/or metastatic squamous cell carcinoma of Head and Neck-V-CHANCE trial. BMC Cancer 16, 918.

Carmody, L.C., Germain, A.R., VerPlank, L., Nag, P.P., Munoz, B., Perez, J.R., and Palmer, M.A. (2012). Phenotypic high-throughput screening elucidates target pathway in breast cancer stem cell-like cells. J Biomol Screen 17, 1204-1210.

Ceppi, P., Mudduluru, G., Kumarswamy, R., Rapa, I., Scagliotti, G.V., Papotti, M., and Allgayer, H. (2010). Loss of miR-200c expression induces an aggressive, invasive, and chemoresistant phenotype in non-small cell lung cancer. Mol Cancer Res 8, 1207-1216.

Chang, C.J., Chao, C.H., Xia, W., Yang, J.Y., Xiong, Y., Li, C.W., Yu, W.H., Rehman, S.K., Hsu, J.L., Lee, H.H., et al. (2011). p53 regulates epithelial- 
mesenchymal transition and stem cell properties through modulating miRNAs. Nat Cell Biol 13, 317-323.

Chen, J., Guo, L., Zhang, L., Wu, H., Yang, J., Liu, H., Wang, X., Hu, X., Gu, T., Zhou, Z., et al. (2013). Vitamin C modulates TET1 function during somatic cell reprogramming. Nat Genet 45, 1504-1509.

Chua, K.N., Kong, L.R., Sim, W.J., Ng, H.C., Ong, W.R., Thiery, J.P., Huynh, H., and Goh, B.C. (2015). Combinatorial treatment using targeted MEK and SRC inhibitors synergistically abrogates tumor cell growth and induces mesenchymalepithelial transition in non-small-cell lung carcinoma. Oncotarget 6, 29991-30005.

Chua, K.N., Sim, W.J., Racine, V., Lee, S.Y., Goh, B.C., and Thiery, J.P. (2012). A cell-based small molecule screening method for identifying inhibitors of epithelialmesenchymal transition in carcinoma. PLoS One 7, e33183.

Chung, V.Y., Tan, T.Z., Tan, M., Wong, M.K., Kuay, K.T., Yang, Z., Ye, J., Muller, J., Koh, C.M., Guccione, E., et al. (2016). GRHL2-miR-200-ZEB1 maintains the epithelial status of ovarian cancer through transcriptional regulation and histone modification. Sci Rep 6, 19943.

dos Santos, R.L., Tosti, L., Radzisheuskaya, A., Caballero, I.M., Kaji, K., Hendrich, B., and Silva, J.C. (2014). MBD3/NuRD facilitates induction of pluripotency in a context-dependent manner. Cell Stem Cell 15, 102-110.

Ebrahimi, B. (2015). Reprogramming barriers and enhancers: strategies to enhance the efficiency and kinetics of induced pluripotency. Cell Regen (Lond) 4, 10.

Ehata, S., Hanyu, A., Fujime, M., Katsuno, Y., Fukunaga, E., Goto, K., Ishikawa, Y., Nomura, K., Yokoo, H., Shimizu, T., et al. (2007). Ki26894, a novel transforming growth factor-beta type I receptor kinase inhibitor, inhibits in vitro invasion and in vivo bone metastasis of a human breast cancer cell line. Cancer Sci 98, 127-133.

Elenbaas, B., Spirio, L., Koerner, F., Fleming, M.D., Zimonjic, D.B., Donaher, J.L., Popescu, N.C., Hahn, W.C., and Weinberg, R.A. (2001). Human breast cancer cells generated by oncogenic transformation of primary mammary epithelial cells. Genes Dev 15, 50-65.

Fan, L.C., Shiau, C.W., Tai, W.T., Hung, M.H., Chu, P.Y., Hsieh, F.S., Lin, H., Yu, H.C., and Chen, K.F. (2015). SHP-1 is a negative regulator of epithelial-mesenchymal transition in hepatocellular carcinoma. Oncogene 34, 5252-5263.

Fan, L.C., Teng, H.W., Shiau, C.W., Tai, W.T., Hung, M.H., Yang, S.H., Jiang, J.K., and Chen, K.F. (2016). Regorafenib (Stivarga) pharmacologically targets epithelialmesenchymal transition in colorectal cancer. Oncotarget 7, 64136-64147.

Feneyrolles, C., Spenlinhauer, A., Guiet, L., Fauvel, B., Dayde-Cazals, B., Warnault, P., Cheve, G., and Yasri, A. (2014). Axl kinase as a key target for oncology: focus on small molecule inhibitors. Mol Cancer Ther 13, 2141-2148.

Fischer, K.R., Durrans, A., Lee, S., Sheng, J., Li, F., Wong, S.T., Choi, H., El Rayes, T., Ryu, S., Troeger, J., et al. (2015). Epithelial-to-mesenchymal transition is not required for lung metastasis but contributes to chemoresistance. Nature.

Flaherty, K.T., Puzanov, I., Kim, K.B., Ribas, A., McArthur, G.A., Sosman, J.A., O'Dwyer, P.J., Lee, R.J., Grippo, J.F., Nolop, K., et al. (2010). Inhibition of mutated, activated BRAF in metastatic melanoma. N Engl J Med 363, 809-819. 
Frederick, B.A., Helfrich, B.A., Coldren, C.D., Zheng, D., Chan, D., Bunn, P.A., Jr., and Raben, D. (2007). Epithelial to mesenchymal transition predicts gefitinib resistance in cell lines of head and neck squamous cell carcinoma and non-small cell lung carcinoma. Mol Cancer Ther 6, 1683-1691.

Fu, H.L., Ma, Y., Lu, L.G., Hou, P., Li, B.J., Jin, W.L., and Cui, D.X. (2014). TET1 exerts its tumor suppressor function by interacting with p53-EZH2 pathway in gastric cancer. J Biomed Nanotechnol 10, 1217-1230.

Fu, J., Qin, L., He, T., Qin, J., Hong, J., Wong, J., Liao, L., and Xu, J. (2011). The TWIST/Mi2/NuRD protein complex and its essential role in cancer metastasis. Cell Res 21, 275-289.

Giannelli, G., Mikulits, W., Dooley, S., Fabregat, I., Moustakas, A., ten Dijke, P., Portincasa, P., Winter, P., Janssen, R., Leporatti, S., et al. (2016). The rationale for targeting TGF-beta in chronic liver diseases. Eur J Clin Invest 46, 349-361.

Giannelli, G., Villa, E., and Lahn, M. (2014). Transforming growth factor-beta as a therapeutic target in hepatocellular carcinoma. Cancer Res 74, 1890-1894.

Granados-Principal, S., Liu, Y., Guevara, M.L., Blanco, E., Choi, D.S., Qian, W., Patel, T., Rodriguez, A.A., Cusimano, J., Weiss, H.L., et al. (2015). Inhibition of iNOS as a novel effective targeted therapy against triple-negative breast cancer. Breast Cancer Res 17, 25.

Green, T.P., Fennell, M., Whittaker, R., Curwen, J., Jacobs, V., Allen, J., Logie, A., Hargreaves, J., Hickinson, D.M., Wilkinson, R.W., et al. (2009). Preclinical anticancer activity of the potent, oral Src inhibitor AZD0530. Mol Oncol 3, 248-261.

Gregorieff, A., Liu, Y., Inanlou, M.R., Khomchuk, Y., Wrana, J.L., 2015. Yapdependent reprogramming of Lgr5(+) stem cells drives intestinal regeneration and cancer. Nature 526, 715-718.

Guo, W., Keckesova, Z., Donaher, J.L., Shibue, T., Tischler, V., Reinhardt, F., Itzkovitz, S., Noske, A., Zurrer-Hardi, U., Bell, G., et al. (2012). Slug and Sox9 cooperatively determine the mammary stem cell state. Cell 148, 1015-1028.

Gupta, P.B., Onder, T.T., Jiang, G., Tao, K., Kuperwasser, C., Weinberg, R.A., and Lander, E.S. (2009). Identification of selective inhibitors of cancer stem cells by highthroughput screening. Cell 138, 645-659.

Han, X., Zhou, Y., You, Y., Lu, J., Wang, L., Hou, H., Li, J., Chen, W., Zhao, L., and $\mathrm{Li}, \mathrm{X}$. (2017). TET1 promotes cisplatin-resistance via demethylating the vimentin promoter in ovarian cancer. Cell Biol Int 41, 405-414.

Hanna, J., Markoulaki, S., Schorderet, P., Carey, B.W., Beard, C., Wernig, M., Creyghton, M.P., Steine, E.J., Cassady, J.P., Foreman, R., et al. (2008). Direct reprogramming of terminally differentiated mature B lymphocytes to pluripotency. Cell 133, 250-264.

Hazzan, M., Hertig, A., Buob, D., Copin, M.C., Noel, C., Rondeau, E., and Dubois$\mathrm{Xu}$, Y.C. (2011). Epithelial-to-mesenchymal transition predicts cyclosporine nephrotoxicity in renal transplant recipients. J Am Soc Nephrol 22, 1375-1381.

Herranz, N., Pasini, D., Diaz, V.M., Franci, C., Gutierrez, A., Dave, N., Escriva, M., Hernandez-Munoz, I., Di Croce, L., Helin, K., et al. (2008). Polycomb complex 2 is 
required for E-cadherin repression by the Snaill transcription factor. Mol Cell Biol 28, 4772-4781.

Hertig, A., Anglicheau, D., Verine, J., Pallet, N., Touzot, M., Ancel, P.Y., Mesnard, L., Brousse, N., Baugey, E., Glotz, D., et al. (2008). Early epithelial phenotypic changes predict graft fibrosis. J Am Soc Nephrol 19, 1584-1591.

Hikichi, T., Matoba, R., Ikeda, T., Watanabe, A., Yamamoto, T., Yoshitake, S., Tamura-Nakano, M., Kimura, T., Kamon, M., Shimura, M., et al. (2013). Transcription factors interfering with dedifferentiation induce cell type-specific transcriptional profiles. Proc Natl Acad Sci U S A 110, 6412-6417.

Ho, R., Papp, B., Hoffman, J.A., Merrill, B.J., and Plath, K. (2013). Stage-specific regulation of reprogramming to induced pluripotent stem cells by Wnt signaling and T cell factor proteins. Cell Rep 3, 2113-2126.

Hong, H., Takahashi, K., Ichisaka, T., Aoi, T., Kanagawa, O., Nakagawa, M., Okita, K., and Yamanaka, S. (2009). Suppression of induced pluripotent stem cell generation by the p53-p21 pathway. Nature 460, 1132-1135.

Hu, X., Zhang, L., Mao, S.Q., Li, Z., Chen, J., Zhang, R.R., Wu, H.P., Gao, J., Guo, F., Liu, W., et al. (2014). Tet and TDG mediate DNA demethylation essential for mesenchymal-to-epithelial transition in somatic cell reprogramming. Cell Stem Cell $14,512-522$.

Huang, R.Y., Wong, M.K., Tan, T.Z., Kuay, K.T., Ng, A.H., Chung, V.Y., Chu, Y.S., Matsumura, N., Lai, H.C., Lee, Y.F., et al. (2013). An EMT spectrum defines an anoikis-resistant and spheroidogenic intermediate mesenchymal state that is sensitive to e-cadherin restoration by a src-kinase inhibitor, saracatinib (AZD0530). Cell Death Dis 4, e915.

Ichida, J.K., Blanchard, J., Lam, K., Son, E.Y., Chung, J.E., Egli, D., Loh, K.M., Carter, A.C., Di Giorgio, F.P., Koszka, K., et al. (2009). A small-molecule inhibitor of tgf-Beta signaling replaces sox 2 in reprogramming by inducing nanog. Cell Stem Cell 5, 491-503.

Iliopoulos, D., Lindahl-Allen, M., Polytarchou, C., Hirsch, H.A., Tsichlis, P.N., and Struhl, K. (2010). Loss of miR-200 inhibition of Suz12 leads to polycomb-mediated repression required for the formation and maintenance of cancer stem cells. Mol Cell 39, 761-772.

Infante, J.R., Camidge, D.R., Mileshkin, L.R., Chen, E.X., Hicks, R.J., Rischin, D., Fingert, H., Pierce, K.J., Xu, H., Roberts, W.G., et al. (2012). Safety, pharmacokinetic, and pharmacodynamic phase I dose-escalation trial of PF-00562271, an inhibitor of focal adhesion kinase, in advanced solid tumors. J Clin Oncol 30, 1527-1533.

Kawamura, T., Suzuki, J., Wang, Y.V., Menendez, S., Morera, L.B., Raya, A., Wahl, G.M., and Belmonte, J.C. (2009). Linking the p53 tumour suppressor pathway to somatic cell reprogramming. Nature 460, 1140-1144.

Khoo, B.L., Lee, S.C., Kumar, P., Tan, T.Z., Warkiani, M.E., Ow, S.G., Nandi, S., Lim, C.T., and Thiery, J.P. (2015). Short-term expansion of breast circulating cancer cells predicts response to anti-cancer therapy. Oncotarget 6, 15578-15593.

Kim, J., Choi, W.J., Moon, S.H., Jung, J., Park, J.K., Kim, S.H., and Lee, J.O. (2015). Micropillar arrays as potential drug screens: Inhibition of micropillar-mediated 
activation of the FAK-Src-paxillin signaling pathway by the CK2 inhibitor CX-4945. Acta Biomater 27, 13-20.

Kim, J., and Hwan Kim, S. (2013). CK2 inhibitor CX-4945 blocks TGF-beta1induced epithelial-to-mesenchymal transition in A549 human lung adenocarcinoma cells. PLoS One 8, e74342.

Kim, L.C., Song, L., and Haura, E.B. (2009). Src kinases as therapeutic targets for cancer. Nat Rev Clin Oncol 6, 587-595.

Kim, T., Veronese, A., Pichiorri, F., Lee, T.J., Jeon, Y.J., Volinia, S., Pineau, P., Marchio, A., Palatini, J., Suh, S.S., et al. (2011). p53 regulates epithelialmesenchymal transition through microRNAs targeting ZEB1 and ZEB2. J Exp Med 208, 875-883.

Kitai, H., Ebi, H., Tomida, S., Floros, K.V., Kotani, H., Adachi, Y., Oizumi, S., Nishimura, M., Faber, A.C., and Yano, S. (2016). Epithelial-to-Mesenchymal Transition Defines Feedback Activation of Receptor Tyrosine Kinase Signaling Induced by MEK Inhibition in KRAS-Mutant Lung Cancer. Cancer Discov 6, 754769.

Koppikar, P., Choi, S.H., Egloff, A.M., Cai, Q., Suzuki, S., Freilino, M., Nozawa, H., Thomas, S.M., Gooding, W.E., Siegfried, J.M., et al. (2008). Combined inhibition of c-Src and epidermal growth factor receptor abrogates growth and invasion of head and neck squamous cell carcinoma. Clin Cancer Res 14, 4284-4291.

Lan, X., Lu, G., Yuan, C., Mao, S., Jiang, W., Chen, Y., Jin, X., and Xia, Q. (2016). Valproic acid (VPA) inhibits the epithelial-mesenchymal transition in prostate carcinoma via the dual suppression of SMAD4. J Cancer Res Clin Oncol 142, 177 185.

Lei, Z.J., Wang, J., Xiao, H.L., Guo, Y., Wang, T., Li, Q., Liu, L., Luo, X., Fan, L.L., Lin, L., et al. (2015). Lysine-specific demethylase 1 promotes the stemness and chemoresistance of $\operatorname{Lgr} 5(+)$ liver cancer initiating cells by suppressing negative regulators of beta-catenin signaling. Oncogene 34, 3188-3198.

Li, D.Q., Yang, Y., and Kumar, R. (2014). MTA family of proteins in DNA damage response: mechanistic insights and potential applications. Cancer Metastasis Rev 33, 993-1000.

Li, R., Liang, J., Ni, S., Zhou, T., Qing, X., Li, H., He, W., Chen, J., Li, F., Zhuang, Q., Qin, B., Xu, J., Li, W., Yang, J., Gan, Y., Qin, D., Feng, S., Song, H., Yang, D., Zhang, B., Zeng, L., Lai, L., Esteban, M.A., Pei, D., 2010. A mesenchymal-toepithelial transition initiates and is required for the nuclear reprogramming of mouse fibroblasts. Cell stem cell 7, 51-63.

Li, Y., Cao, H., Jiao, Z., Pakala, S.B., Sirigiri, D.N., Li, W., Kumar, R., and Mishra, L. (2010). Carcinoembryonic antigen interacts with TGF-\{beta\} receptor and inhibits TGF- $\{$ beta $\}$ signaling in colorectal cancers. Cancer Res 70, 8159-8168.

Lim, Y.Y., Wright, J.A., Attema, J.L., Gregory, P.A., Bert, A.G., Smith, E., Thomas, D., Lopez, A.F., Drew, P.A., Khew-Goodall, Y., et al. (2013). Epigenetic modulation of the miR-200 family is associated with transition to a breast cancer stem-cell-like state. J Cell Sci 126, 2256-2266. 
Lin, T., Ponn, A., Hu, X., Law, B.K., and Lu, J. (2010a). Requirement of the histone demethylase LSD1 in Snail-mediated transcriptional repression during epithelialmesenchymal transition. Oncogene 29, 4896-4904.

Lin, Y., Wu, Y., Li, J., Dong, C., Ye, X., Chi, Y.I., Evers, B.M., and Zhou, B.P. (2010b). The SNAG domain of Snaill functions as a molecular hook for recruiting lysine-specific demethylase 1. Embo j 29, 1803-1816.

Lluis, F., Pedone, E., Pepe, S., and Cosma, M.P. (2008). Periodic activation of Wnt/beta-catenin signaling enhances somatic cell reprogramming mediated by cell fusion. Cell Stem Cell 3, 493-507.

Lu, D., Choi, M.Y., Yu, J., Castro, J.E., Kipps, T.J., and Carson, D.A. (2011). Salinomycin inhibits Wnt signaling and selectively induces apoptosis in chronic lymphocytic leukemia cells. Proc Natl Acad Sci U S A 108, 13253-13257.

Lv, T., Yuan, D., Miao, X., Lv, Y., Zhan, P., Shen, X., and Song, Y. (2012). Overexpression of LSD1 promotes proliferation, migration and invasion in non-small cell lung cancer. PLoS One 7, e35065.

Maherali, N., and Hochedlinger, K. (2009). Tgfbeta signal inhibition cooperates in the induction of iPSCs and replaces Sox2 and cMyc. Curr Biol 19, 1718-1723.

Mai, T.T., Hamaï, A., Hienzsch, A., Cañeque, T., Müller, S., Wicinski, J.C., O., Leroy, C., David, A., Acevedo, V., Ryo A, G.C., et al. (2017). Salinomycin kills cancer stem cells by sequestering iron in lysosomes. Nature Chemistry in press.

Manchado, E., Weissmueller, S., Morris, J.P.t., Chen, C.C., Wullenkord, R., Lujambio, A., de Stanchina, E., Poirier, J.T., Gainor, J.F., Corcoran, R.B., et al. (2016). A combinatorial strategy for treating KRAS-mutant lung cancer. Nature 534, 647-651.

Mani, S.A., Guo, W., Liao, M.J., Eaton, E.N., Ayyanan, A., Zhou, A.Y., Brooks, M., Reinhard, F., Zhang, C.C., Shipitsin, M., et al. (2008). The epithelial-mesenchymal transition generates cells with properties of stem cells. Cell 133, 704-715.

Marion, R.M., Strati, K., Li, H., Murga, M., Blanco, R., Ortega, S., FernandezCapetillo, O., Serrano, M., and Blasco, M.A. (2009). A p53-mediated DNA damage response limits reprogramming to ensure iPS cell genomic integrity. Nature 460, 1149-1153.

McDonald, O.G., Wu, H., Timp, W., Doi, A., and Feinberg, A.P. (2011). Genomescale epigenetic reprogramming during epithelial-to-mesenchymal transition. Nat Struct Mol Biol 18, 867-874.

Meidhof, S., Brabletz, S., Lehmann, W., Preca, B.T., Mock, K., Ruh, M., Schuler, J., Berthold, M., Weber, A., Burk, U., et al. (2015). ZEB1-associated drug resistance in cancer cells is reversed by the class I HDAC inhibitor mocetinostat. EMBO Mol Med 7, 831-847.

Melisi, D., Ishiyama, S., Sclabas, G.M., Fleming, J.B., Xia, Q., Tortora, G., Abbruzzese, J.L., and Chiao, P.J. (2008). LY2109761, a novel transforming growth factor beta receptor type I and type II dual inhibitor, as a therapeutic approach to suppressing pancreatic cancer metastasis. Mol Cancer Ther 7, 829-840. 
Morel, A.P., Lievre, M., Thomas, C., Hinkal, G., Ansieau, S., and Puisieux, A. (2008). Generation of breast cancer stem cells through epithelial-mesenchymal transition. PLoS One 3, e2888.

Mu, P., Zhang, Z., Benelli, M., Karthaus, W.R., Hoover, E., Chen, C.C., Wongvipat, J., Ku, S.Y., Gao, D., Cao, Z., Shah, N., Adams, E.J., Abida, W., Watson, P.A., Prandi, D., Huang, C.H., de Stanchina, E., Lowe, S.W., Ellis, L., Beltran, H., Rubin, M.A., Goodrich, D.W., Demichelis, F., Sawyers, C.L., 2017. SOX2 promotes lineage plasticity and antiandrogen resistance in TP53- and RB1-deficient prostate cancer. Science 355, 84-88.

Nagasawa, S., Sedukhina, A.S., Nakagawa, Y., Maeda, I., Kubota, M., Ohnuma, S., Tsugawa, K., Ohta, T., Roche-Molina, M., Bernal, J.A., et al. (2015). LSD1 overexpression is associated with poor prognosis in basal-like breast cancer, and sensitivity to PARP inhibition. PLoS One 10, e0118002.

Nieto, M.A. (2013). Epithelial plasticity: a common theme in embryonic and cancer cells. Science 342, 1234850.

Nieto, M.A., Huang, R.Y., Jackson, R.A., and Thiery, J.P. (2016). EMT: 2016. Cell 166, 21-45.

Ocana, O.H., Corcoles, R., Fabra, A., Moreno-Bueno, G., Acloque, H., Vega, S., Barrallo-Gimeno, A., Cano, A., and Nieto, M.A. (2012). Metastatic colonization requires the repression of the epithelial-mesenchymal transition inducer Prrx1. Cancer Cell 22, 709-724.

Park, C.Y., Kim, D.K., and Sheen, Y.Y. (2011a). EW-7203, a novel small molecule inhibitor of transforming growth factor-beta (TGF-beta) type I receptor/activin receptor-like kinase-5, blocks TGF-betal-mediated epithelial-to-mesenchymal transition in mammary epithelial cells. Cancer Sci 102, 1889-1896.

Park, C.Y., Son, J.Y., Jin, C.H., Nam, J.S., Kim, D.K., and Sheen, Y.Y. (2011b). EW7195, a novel inhibitor of ALK5 kinase inhibits EMT and breast cancer metastasis to lung. Eur J Cancer 47, 2642-2653.

Park, I.K., Morrison, S.J., and Clarke, M.F. (2004). Bmi1, stem cells, and senescence regulation. J Clin Invest 113, 175-179.

Pattabiraman, D.R., Bierie, B., Kober, K.I., Thiru, P., Krall, J.A., Zill, C., Reinhardt, F., Tam, W.L., and Weinberg, R.A. (2016). Activation of PKA leads to mesenchymal-to-epithelial transition and loss of tumor-initiating ability. Science 351, $\operatorname{aad} 3680$.

Peinado, H., Ballestar, E., Esteller, M., and Cano, A. (2004). Snail mediates Ecadherin repression by the recruitment of the $\operatorname{Sin} 3 \mathrm{~A} /$ histone deacetylase 1 (HDAC1)/HDAC2 complex. Mol Cell Biol 24, 306-319.

Popowski, M., Templeton, T.D., Lee, B.K., Rhee, C., Li, H., Miner, C., Dekker, J.D., Orlanski, S., Bergman, Y., Iyer, V.R., et al. (2014). Bright/Arid3A acts as a barrier to somatic cell reprogramming through direct regulation of Oct4, Sox2, and Nanog. Stem Cell Reports 2, 26-35.

Puls, L.N., Eadens, M., and Messersmith, W. (2011). Current status of SRC inhibitors in solid tumor malignancies. Oncologist $16,566-578$. 
Qin, H., Blaschke, K., Wei, G., Ohi, Y., Blouin, L., Qi, Z., Yu, J., Yeh, R.F., Hebrok, M., and Ramalho-Santos, M. (2012). Transcriptional analysis of pluripotency reveals the Hippo pathway as a barrier to reprogramming. Hum Mol Genet 21, 2054-2067.

Qin, H., Diaz, A., Blouin, L., Lebbink, R.J., Patena, W., Tanbun, P., LeProust, E.M., McManus, M.T., Song, J.S., and Ramalho-Santos, M. (2014). Systematic identification of barriers to human iPSC generation. Cell 158, 449-461.

Rausch, M.P., Hahn, T., Ramanathapuram, L., Bradley-Dunlop, D., Mahadevan, D., Mercado-Pimentel, M.E., Runyan, R.B., Besselsen, D.G., Zhang, X., Cheung, H.K., et al. (2009). An orally active small molecule TGF-beta receptor I antagonist inhibits the growth of metastatic murine breast cancer. Anticancer Res 29, 2099-2109.

Reichl, P., Dengler, M., van Zijl, F., Huber, H., Fuhrlinger, G., Reichel, C., Sieghart, W., Peck-Radosavljevic, M., Grubinger, M., and Mikulits, W. (2015). Axl activates autocrine transforming growth factor-beta signaling in hepatocellular carcinoma. Hepatology 61, 930-941.

Rios, A.C., Fu, N.Y., Cursons, J., Lindeman, G.J., and Visvader, J.E. (2016). The complexities and caveats of lineage tracing in the mammary gland. Breast Cancer Res $18,116$.

Rodon, J., Carducci, M., Sepulveda-Sanchez, J.M., Azaro, A., Calvo, E., Seoane, J., Brana, I., Sicart, E., Gueorguieva, I., Cleverly, A., et al. (2015). Pharmacokinetic, pharmacodynamic and biomarker evaluation of transforming growth factor-beta receptor I kinase inhibitor, galunisertib, in phase 1 study in patients with advanced cancer. Invest New Drugs 33, 357-370.

Rosano, L., Di Castro, V., Spinella, F., Nicotra, M.R., Natali, P.G., and Bagnato, A. (2007). ZD4054, a specific antagonist of the endothelin A receptor, inhibits tumor growth and enhances paclitaxel activity in human ovarian carcinoma in vitro and in vivo. Mol Cancer Ther 6, 2003-2011.

Rosano, L., Spinella, F., Di Castro, V., Nicotra, M.R., Dedhar, S., de Herreros, A.G., Natali, P.G., and Bagnato, A. (2005). Endothelin-1 promotes epithelial-tomesenchymal transition in human ovarian cancer cells. Cancer Res 65, 11649-11657.

Rostaing, L., Hertig, A., Albano, L., Anglicheau, D., Durrbach, A., Vuiblet, V., Moulin, B., Merville, P., Hazzan, M., Lang, P., et al. (2015). Fibrosis progression according to epithelial-mesenchymal transition profile: a randomized trial of everolimus versus CsA. Am J Transplant 15, 1303-1312.

Sakamoto, T., Kobayashi, S., Yamada, D., Nagano, H., Tomokuni, A., Tomimaru, Y., Noda, T., Gotoh, K., Asaoka, T., Wada, H., et al. (2016). A Histone Deacetylase Inhibitor Suppresses Epithelial-Mesenchymal Transition and Attenuates Chemoresistance in Biliary Tract Cancer. PLoS One 11, e0145985.

Sato, H., Shien, K., Tomida, S., Okayasu, K., Suzawa, K., Hashida, S., Torigoe, H., Watanabe, M., Yamamoto, H., Soh, J., et al. (2017). Targeting the miR-200c/LIN28B axis in acquired EGFR-TKI resistance non-small cell lung cancer cells harboring EMT features. Sci Rep 7, 40847.

Schech, A., Kazi, A., Yu, S., Shah, P., and Sabnis, G. (2015). Histone Deacetylase Inhibitor Entinostat Inhibits Tumor-Initiating Cells in Triple-Negative Breast Cancer Cells. Mol Cancer Ther 14, 1848-1857. 
Scheel, C., Eaton, E.N., Li, S.H., Chaffer, C.L., Reinhardt, F., Kah, K.J., Bell, G., Guo, W., Rubin, J., Richardson, A.L., et al. (2011). Paracrine and autocrine signals induce and maintain mesenchymal and stem cell states in the breast. In Cell (United States: 2011 Elsevier Inc), pp. 926-940.

Schobert, R., and Biersack, B. (2017). Multimodal HDAC inhibitors with improved anticancer activity. Curr Cancer Drug Targets.

Shao, D.D., Xue, W., Krall, E.B., Bhutkar, A., Piccioni, F., Wang, X., Schinzel, A.C., Sood, S., Rosenbluh, J., Kim, J.W., et al. (2014). KRAS and YAP1 converge to regulate EMT and tumor survival. Cell 158, 171-184.

Shi, Y., Lan, F., Matson, C., Mulligan, P., Whetstine, J.R., Cole, P.A., Casero, R.A., and Shi, Y. (2004). Histone demethylation mediated by the nuclear amine oxidase homolog LSD1. Cell 119, 941-953.

Smith, Z.D., Sindhu, C., Meissner, A., 2016. Molecular features of cellular reprogramming and development. Nature reviews. Molecular cell biology 17, 139154.

Son, J.Y., Park, S.Y., Kim, S.J., Lee, S.J., Park, S.A., Kim, M.J., Kim, S.W., Kim, D.K., Nam, J.S., and Sheen, Y.Y. (2014). EW-7197, a novel ALK-5 kinase inhibitor, potently inhibits breast to lung metastasis. Mol Cancer Ther 13, 1704-1716.

Song, L.B., Li, J., Liao, W.T., Feng, Y., Yu, C.P., Hu, L.J., Kong, Q.L., Xu, L.H., Zhang, X., Liu, W.L., et al. (2009). The polycomb group protein Bmi-1 represses the tumor suppressor PTEN and induces epithelial-mesenchymal transition in human nasopharyngeal epithelial cells. J Clin Invest 119, 3626-3636.

Song, S.J., Poliseno, L., Song, M.S., Ala, U., Webster, K., Ng, C., Beringer, G., Brikbak, N.J., Yuan, X., Cantley, L.C., et al. (2013). MicroRNA-antagonism regulates breast cancer stemness and metastasis via TET-family-dependent chromatin remodeling. Cell 154, 311-324.

Sun, M., Song, C.X., Huang, H., Frankenberger, C.A., Sankarasharma, D., Gomes, S., Chen, P., Chen, J., Chada, K.K., He, C., et al. (2013). HMGA2/TET1/HOXA9 signaling pathway regulates breast cancer growth and metastasis. Proc Natl Acad Sci U S A 110, 9920-9925.

Takahashi, K., Yamanaka, S., 2006. Induction of pluripotent stem cells from mouse embryonic and adult fibroblast cultures by defined factors. Cell 126, 663-676.

Tam, W.L., Lu, H., Buikhuisen, J., Soh, B.S., Lim, E., Reinhardt, F., Wu, Z.J., Krall, J.A., Bierie, B., Guo, W., et al. (2013). Protein kinase C alpha is a central signaling node and therapeutic target for breast cancer stem cells. Cancer Cell 24, 347-364.

Tam, W.L., and Weinberg, R.A. (2013). The epigenetics of epithelial-mesenchymal plasticity in cancer. Nat Med 19, 1438-1449.

Tang, H.M., Kuay, K.T., Koh, P.F., Asad, M., Tan, T.Z., Chung, V.Y., Lee, S.C., Thiery, J.P., and Huang, R.J. (2016). An epithelial marker promoter induction screen identifies histone deacetylase inhibitors to restore epithelial differentiation and abolishes anchorage independence growth in cancers. Cell Death Discov 2, 16041.

Tetteh, P.W., Basak, O., Farin, H.F., Wiebrands, K., Kretzschmar, K., Begthel, H., van den Born, M., Korving, J., de Sauvage, F., van Es, J.H., van Oudenaarden, A., 
Clevers, H., 2016. Replacement of Lost Lgr5-Positive Stem Cells through Plasticity of Their Enterocyte-Lineage Daughters. Cell stem cell 18, 203-213.

Thiery, J.P., Acloque, H., Huang, R.Y., and Nieto, M.A. (2009). Epithelialmesenchymal transitions in development and disease. Cell 139, 871-890.

Thomson, S., Buck, E., Petti, F., Griffin, G., Brown, E., Ramnarine, N., Iwata, K.K., Gibson, N., and Haley, J.D. (2005). Epithelial to mesenchymal transition is a determinant of sensitivity of non-small-cell lung carcinoma cell lines and xenografts to epidermal growth factor receptor inhibition. Cancer Res 65, 9455-9462.

Tryndyak, V.P., Beland, F.A., and Pogribny, I.P. (2010). E-cadherin transcriptional down-regulation by epigenetic and microRNA-200 family alterations is related to mesenchymal and drug-resistant phenotypes in human breast cancer cells. Int $\mathbf{J}$ Cancer 126, 2575-2583.

Tsai, J.H., Donaher, J.L., Murphy, D.A., Chau, S., and Yang, J. (2012). Spatiotemporal regulation of epithelial-mesenchymal transition is essential for squamous cell carcinoma metastasis. Cancer Cell 22, 725-736.

Tsai, Y.P., Chen, H.F., Chen, S.Y., Cheng, W.C., Wang, H.W., Shen, Z.J., Song, C., Teng, S.C., He, C., and Wu, K.J. (2014). TET1 regulates hypoxia-induced epithelialmesenchymal transition by acting as a co-activator. Genome Biol 15, 513.

Valk-Lingbeek, M.E., Bruggeman, S.W., and van Lohuizen, M. (2004). Stem cells and cancer; the polycomb connection. Cell 118, 409-418.

van de Moosdijk, A.A., Fu, N.Y., Rios, A.C., Visvader, J.E., and van Amerongen, R. (2017). Lineage Tracing of Mammary Stem and Progenitor Cells. Methods Mol Biol 1501, 291-308.

van Es, J.H., Sato, T., van de Wetering, M., Lyubimova, A., Nee, A.N., Gregorieff, A., Sasaki, N., Zeinstra, L., van den Born, M., Korving, J., et al. (2012). D111+ secretory progenitor cells revert to stem cells upon crypt damage. Nat Cell Biol 14, 1099-1104.

Vidal, S.E., Amlani, B., Chen, T., Tsirigos, A., and Stadtfeld, M. (2014). Combinatorial modulation of signaling pathways reveals cell-type-specific requirements for highly efficient and synchronous iPSC reprogramming. Stem Cell Reports 3, 574-584.

von Burstin, J., Eser, S., Paul, M.C., Seidler, B., Brandl, M., Messer, M., von Werder, A., Schmidt, A., Mages, J., Pagel, P., et al. (2009). E-cadherin regulates metastasis of pancreatic cancer in vivo and is suppressed by a SNAIL/HDAC1/HDAC2 repressor complex. Gastroenterology 137, 361-371, 371.e361-365.

Voon, D.C., and Thiery, J.P. (2017). The Emerging Roles of RUNX Transcription Factors in Epithelial-Mesenchymal Transition. Adv Exp Med Biol 962, 471-489.

Voon, D.C., Wang, H., Koo, J.K., Nguyen, T.A., Hor, Y.T., Chu, Y.S., Ito, K., Fukamachi, H., Chan, S.L., Thiery, J.P., et al. (2012). Runx3 protects gastric epithelial cells against epithelial-mesenchymal transition-induced cellular plasticity and tumorigenicity. Stem Cells 30, 2088-2099.

Vultur, A., Buettner, R., Kowolik, C., Liang, W., Smith, D., Boschelli, F., and Jove, R. (2008). SKI-606 (bosutinib), a novel Src kinase inhibitor, suppresses migration and invasion of human breast cancer cells. Mol Cancer Ther 7, 1185-1194. 
Xia, H., Ooi, L.L., and Hui, K.M. (2013). MicroRNA-216a/217-induced epithelialmesenchymal transition targets PTEN and SMAD7 to promote drug resistance and recurrence of liver cancer. Hepatology 58, 629-641.

Xu, Y., Qin, L., Sun, T., Wu, H., He, T., Yang, Z., Mo, Q., Liao, L., and Xu, J. (2017). Twist 1 promotes breast cancer invasion and metastasis by silencing Foxal expression. Oncogene 36, 1157-1166.

Yadavalli, S., Jayaram, S., Manda, S.S., Madugundu, A.K., Nayakanti, D.S., Tan, T.Z., Bhat, R., Rangarajan, A., Chatterjee, A., Gowda, H., et al. (2017). Data-Driven Discovery of Extravasation Pathway in Circulating Tumor Cells. Sci Rep 7, 43710.

Yang, M.H., Hsu, D.S., Wang, H.W., Wang, H.J., Lan, H.Y., Yang, W.H., Huang, C.H., Kao, S.Y., Tzeng, C.H., Tai, S.K., et al. (2010). Bmil is essential in Twist1induced epithelial-mesenchymal transition. Nat Cell Biol 12, 982-992.

Yano, S., Wang, W., Li, Q., Matsumoto, K., Sakurama, H., Nakamura, T., Ogino, H., Kakiuchi, S., Hanibuchi, M., Nishioka, Y., et al. (2008). Hepatocyte growth factor induces gefitinib resistance of lung adenocarcinoma with epidermal growth factor receptor-activating mutations. Cancer Res 68, 9479-9487.

Ye, X., Tam, W.L., Shibue, T., Kaygusuz, Y., Reinhardt, F., Ng Eaton, E., and Weinberg, R.A. (2015). Distinct EMT programs control normal mammary stem cells and tumour-initiating cells. Nature 525, 256-260.

Yu, M., Bardia, A., Wittner, B.S., Stott, S.L., Smas, M.E., Ting, D.T., Isakoff, S.J., Ciciliano, J.C., Wells, M.N., Shah, A.M., et al. (2013a). Circulating breast tumor cells exhibit dynamic changes in epithelial and mesenchymal composition. Science 339, 580-584.

Yu, Y., Wang, B., Zhang, K., Lei, Z., Guo, Y., Xiao, H., Wang, J., Fan, L., Lan, C., Wei, Y., et al. (2013b). High expression of lysine-specific demethylase 1 correlates with poor prognosis of patients with esophageal squamous cell carcinoma. Biochem Biophys Res Commun 437, 192-198.

Yun-Ju Huang, R., and Yo-Yan Huang, T. (2016). A new dimension in drug discovery: reversing epithelial-mesenchymal transition (EMT). Cell Death Dis 7, e2417.

Zhang, B., Halder, S.K., Zhang, S., and Datta, P.K. (2009). Targeting transforming growth factor-beta signaling in liver metastasis of colon cancer. Cancer Lett 277, 114120.

Zhao, Z.K., Yu, H.F., Wang, D.R., Dong, P., Chen, L., Wu, W.G., Ding, W.J., and Liu, Y.B. (2012). Overexpression of lysine specific demethylase 1 predicts worse prognosis in primary hepatocellular carcinoma patients. World J Gastroenterol 18, 6651-6656.

Zheng, X., Carstens, J.L., Kim, J., Scheible, M., Kaye, J., Sugimoto, H., Wu, C.C., LeBleu, V.S., and Kalluri, R. (2015). Epithelial-to-mesenchymal transition is dispensable for metastasis but induces chemoresistance in pancreatic cancer. Nature.

Zhou, J.N., Zeng, Q., Wang, H.Y., Zhang, B., Li, S.T., Nan, X., Cao, N., Fu, C.J., Yan, X.L., Jia, Y.L., et al. (2015). MicroRNA-125b attenuates epithelialmesenchymal transitions and targets stem-like liver cancer cells through small mothers against decapentaplegic 2 and 4. Hepatology 62, 801-815. 
Zou, J., Luo, H., Zeng, Q., Dong, Z., Wu, D., and Liu, L. (2011). Protein kinase CK2alpha is overexpressed in colorectal cancer and modulates cell proliferation and invasion via regulating EMT-related genes. J Transl Med 9, 97.

Zucali, P.A., Ruiz, M.G., Giovannetti, E., Destro, A., Varella-Garcia, M., Floor, K., Ceresoli, G.L., Rodriguez, J.A., Garassino, I., Comoglio, P., et al. (2008). Role of cMET expression in non-small-cell lung cancer patients treated with EGFR tyrosine kinase inhibitors. Ann Oncol 19, 1605-1612. 